\title{
Evaluation of dynamic properties of traditional wooden shrines in Yurihonjo, Japan
}

\author{
C. Cuadra, Y. Yamada \& R. Narumi \\ Akita Prefectural University, Japan
}

\begin{abstract}
Japanese traditional wooden shrines located in Yurihonjo city are investigated to evaluate their dynamic characteristics and seismic performance. Some of the selected constructions for this research are declared as buildings of cultural interest by the local government and therefore efforts are made to preserve these kinds of buildings. The structure corresponds in general to framed wooden constructions with traditional connections between columns and beams. In general, nails are not used in these joints, and instead, the beams are narrowed at the extreme to be inserted into a hole cut in the columns. These buildings are supported by columns that rest directly on stone bases forming a kind of pinned joints. Ambient vibration measurements of the buildings were planned and undertaken by the authors. A comparative study of the predominant periods of the structures is done by plotting the periods versus building heights. Preliminary results show that wooden temples in this region have long periods in comparison to temples of other regions of Japan. The damping ratio was estimated from a free vibration portion of the response curve after the impulse force given by a person. The damping ratios are compared by considering the influence of the number of bays and the dimension of the frame structure in each direction. Ambient vibration measurements provided a valuable basis for evaluation of the dynamic characteristics of wooden heritage structures.
\end{abstract}

Keywords: wooden frame, ambient vibration, period, damping ratio.

\section{Introduction}

Evaluation of dynamic characteristics of traditional wooden shrines is important task as a first step for conservation and restoration purposes. In this research, traditional shrines located in Yurihonjo city, Japan are investigated. Part of the 
selected constructions is declared as buildings of cultural interest by the local government and therefore efforts are done to preserve this kind of buildings. In addition temples that are not cultural heritage are included due to their importance in relation to traditional festivals that are held in these places. Structures correspond in general to framed wooden constructions with traditional connections between columns and beams. In general, nails are not used in these joints, and instead of them, the beams are narrowed at extreme to be inserted into a hole cut in the columns. These buildings are supported by columns that rest directly on stone bases forming a kind of pinned joints.

Ambient vibration measurements on the selected temples were planned and undertaken by the authors. Comparative study of the predominant periods of the structures is done by plotting the periods versus building heights since it is considered that the height of the building affects mainly the period of vibration. Preliminary results show that wooden temples in this region have long periods in comparison to temples of other regions of Japan.

In the case of damping it is considered that this factor is affected strongly by the number and type of joints where the energy dissipation occurs. Damping ratios were estimated from free vibration portion of the response curve after the impulse force given by a person. The damping ratios are compared by considering the influence of the number of bays and the dimension of the frame structure in each direction. Also effect of the connection between the upper part of the columns and the roof is investigated by comparing the damping ratio distribution. It was supposed that the intricate joint could have higher damping than the simple joint. However, the intricate connections, apparently provides larger stiffness to the joint and therefore the damping becomes smaller.

Ambient vibration measurements provided valuable basis for evaluation of the dynamic characteristics of wooden heritage structures and provides reference data for future modeling and analysis of this kind of structures.

\section{Target shrines}

In Yurihonjo city area there are 11 temples that are declared as local cultural heritage, and for this study 9 of these temples were selected. In addition 3 temples that are not architectural heritage were considered for this study. Ambient vibration measurements and the correspondent analysis were performed in these selected buildings. Details of selected structures are shown in Figure 1. The dimensions of these buildings range from approximately $5 \mathrm{~m}$ by $5 \mathrm{~m}$ for the smallest to $10 \mathrm{~m}$ by $10 \mathrm{~m}$ for the largest dimensions in the plan.

The Honjo Hachiman temple, the Hie temple and the Shinzan temple are those that are not declared as architectural heritage. However in these temples important festivals are held every year and these festivals are by themselves cultural events declared as cultural heritages.

In Figure 1 nine temples of those declared as architectural heritage are shown. With exception of Tokusawa Fudou Sondou (Tokusawa) temple that is located near a vegetable field, all temples are located in the upper part of hills. The structure of all temples corresponds to a traditional wooden frame. The 

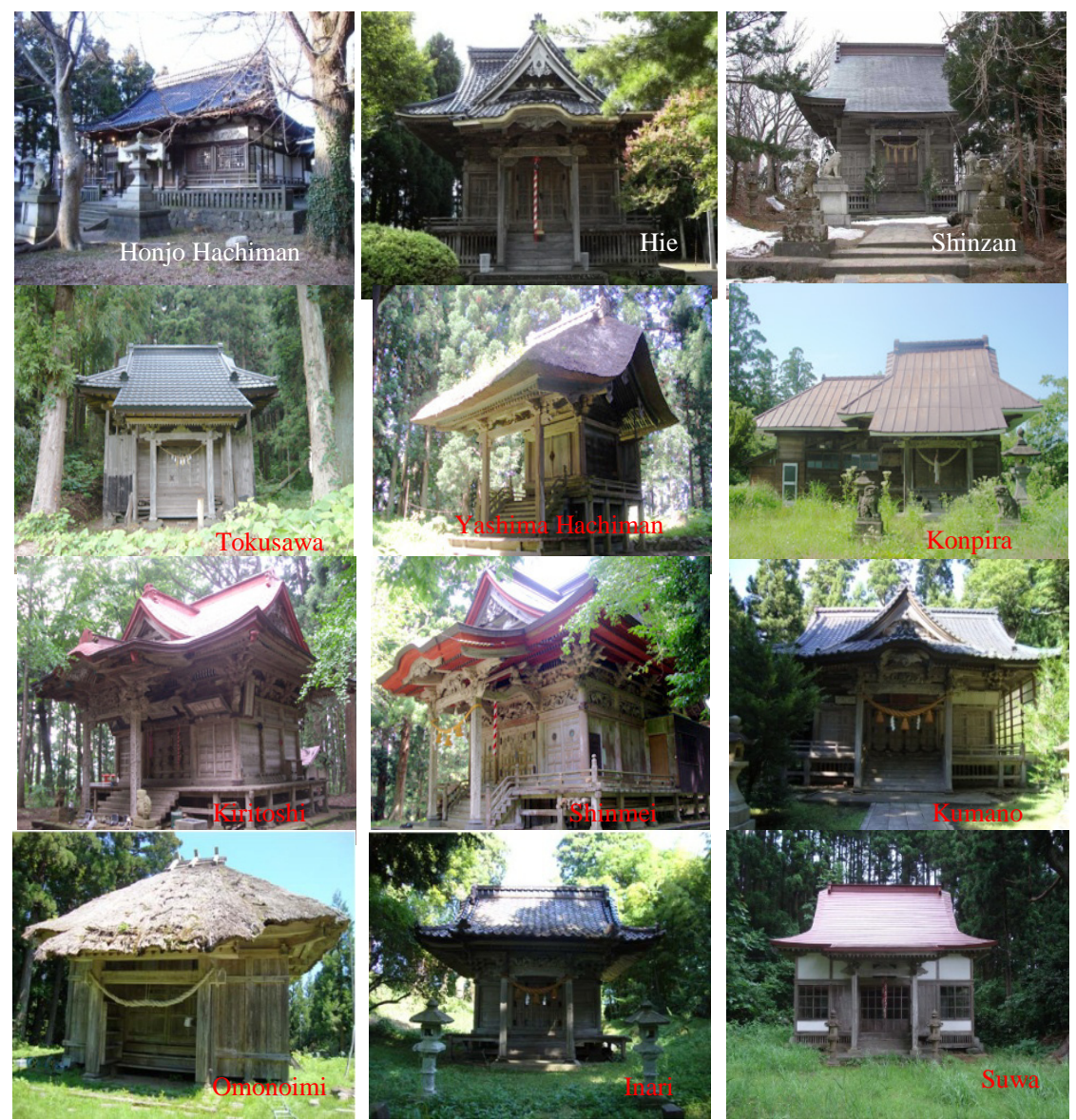

Figure 1: $\quad$ Target shrines.

Tokusawa temple, Kumano temple and Inari temple have tile roof, the Yashima Hachiman and Omonoimi thatched roof and the Konpira, Kiritoshi and Shinmei have thin steel plates as roof.

Damage were observed mainly in temples that are declared as cultural heritage, since they are located usually on top of hills and therefore it is difficult to provide good maintenance. The temples that are not architectural heritage have a better maintenance since they are venues for annual festivals and are located inside cities or towns. The main damage observed in the selected places was the gap between the base stone and the bottom part of the columns as can be observed in Figure 2. Apparently, this failure is due to the deformation of the girders of the bottom part of the structure. In some cases the failure is a combination of the settlement for the central part of the building with the bending of the girder. Also some elements are seriously deteriorated by 
the weather action. In all of the cases was observed that the maintenance of the temples are poor and administration and management offices are always closed if they exist and in other cases there are no administration offices.
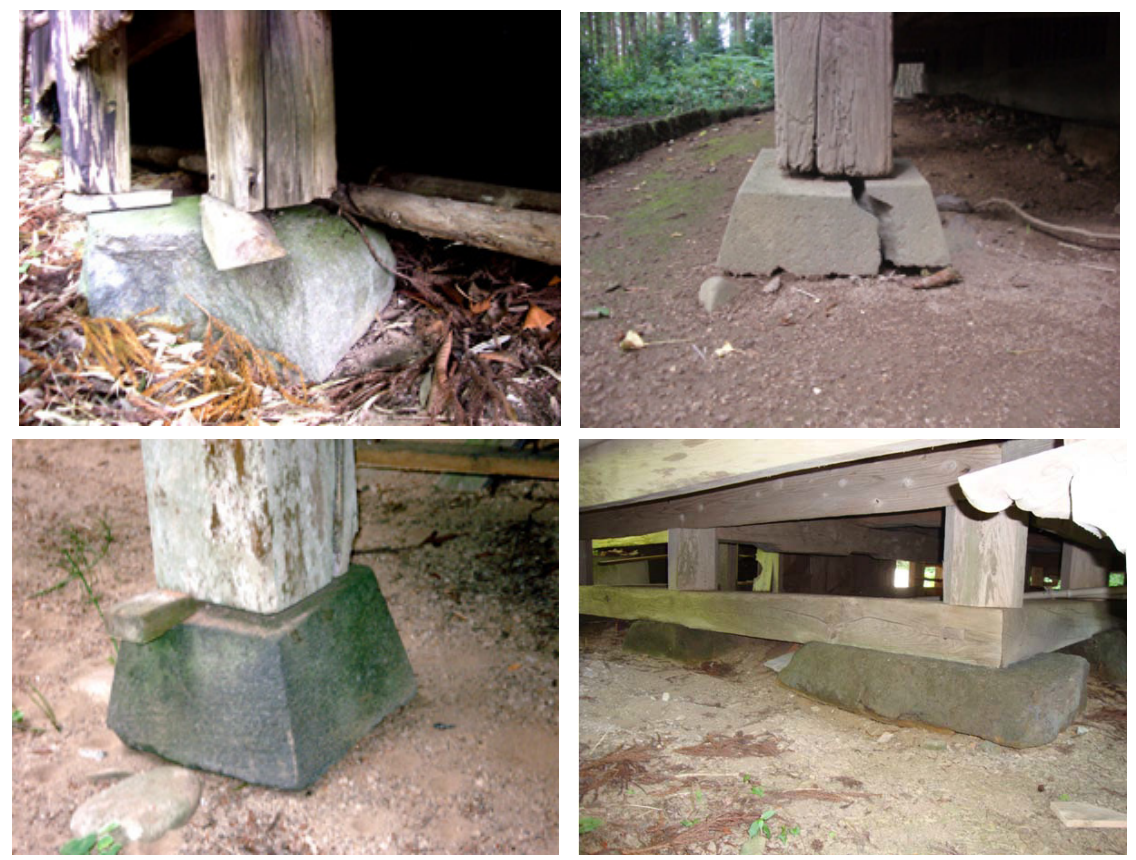

Figure 2: Details of the damage at the bottom of columns.

\section{Ambient vibration measurements}

Ambient vibrations of the selected temples were measured according to the scheme that is shown in Figure 3. One sensor was located on ground site (ch1) and four sensors were located at each corner or near the 4 corners of the building and on the upper beam of the first floor (ch3, ch4, ch5 and ch6). Additional sensor was located at bottom part of the first floor (ch2). Measurements were performed separately for the two principal directions of the temples. To obtain the elastic viscous damping factor at the beginning of each measurement an impact force of a person was used to produce a free dumped vibration. In addition to the set of measurement for the building, the 3 components of the ground vibration were measured for each site to estimate the ground vibration characteristics by using the $\mathrm{H} / \mathrm{V}$ spectrum method. In all cases the sampling frequency was $100 \mathrm{~Hz}$.

The results of measurement on temple buildings are presented for the main or span direction that is parallel to the façade and for the ridge direction. Simultaneous measurements were obtained for building and ground to estimate 


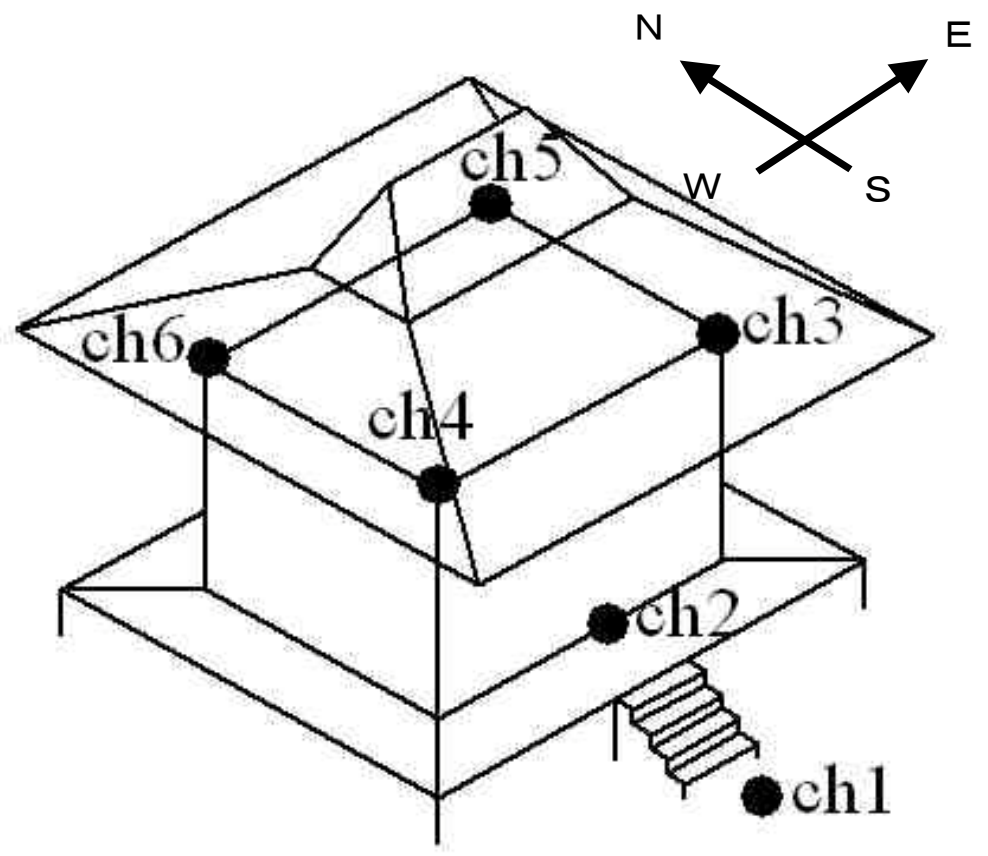

Figure 3: $\quad$ General scheme for points of measurements.

the building characteristics from transfer function however, the Fourier spectrum of the signal at the upper part of the building gives the same results. Therefore only Fourier spectrum is used to estimate the predominant period of the temples. Moreover, to estimate the torsional mode of vibration Fourier spectrum of the relative velocity between two points of measurements is used. As example, the results of the Fourier analysis for Tokusawa temple are show in Figure 4 and Figure 5. Figure 4 shows the results for each horizontal direction and the predominant frequencies are estimated as $3.37 \mathrm{~Hz}$ for the main direction and 2.78 for the transversal direction.

A second peak near $4 \mathrm{~Hz}$ can be appreciated in both cases of Figure 4 therefore is presumed that this peak corresponds to the torsional mode of vibration. To confirm this assumption Fourier spectrum of the relative velocity of two points (for example the difference between ch3 and ch5 in the EW direction) was calculated and the result is presented in Figure 5. For comparison the results of Fourier analysis for the two horizontal directions are also plotted. It can be observed that a clear peak at $3.78 \mathrm{~Hz}$ is obtained. 

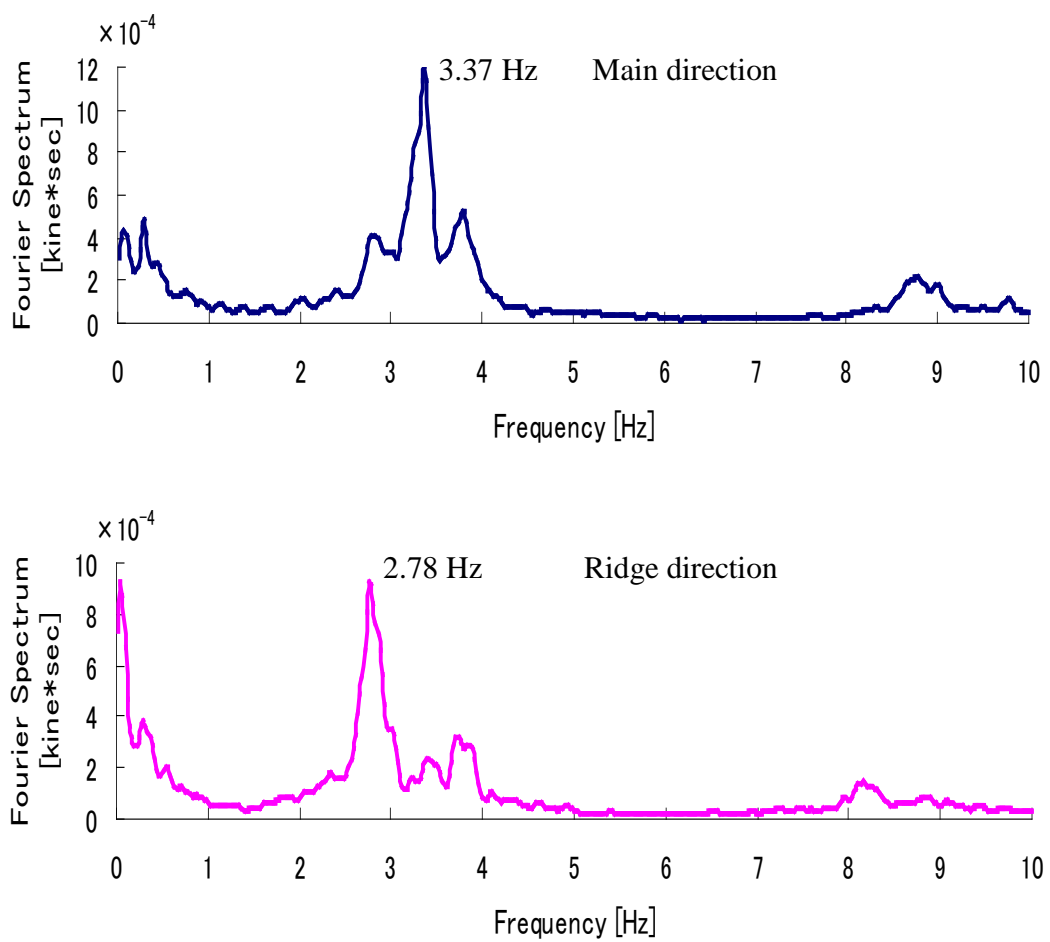

Figure 4: $\quad$ Fourier analysis results for Tokusawa temple.

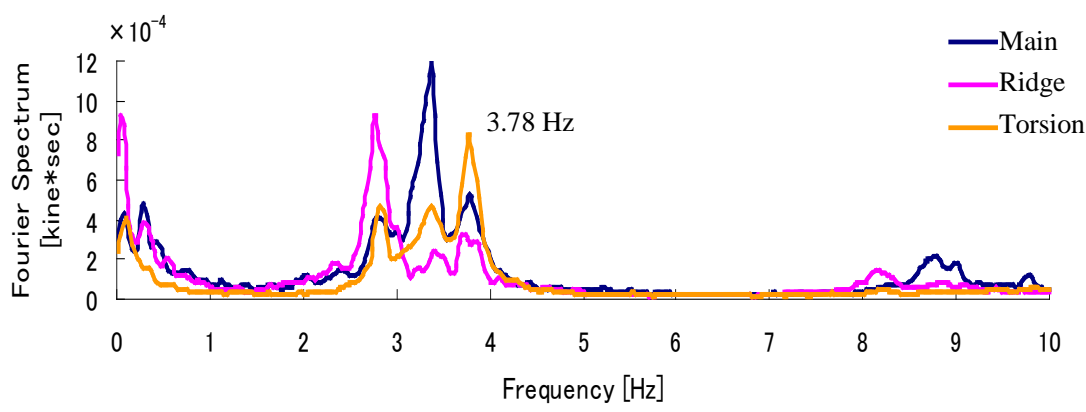

Figure 5: $\quad$ Fourier spectrum of relative velocity for Tokusawa temple.

In Table 1 the results for selected temples are summarized. Results of predominant modes of vibration are expressed in terms of the period of vibration. In this table the calculated damping factors of the temples are also included. 
Table 1: Periods of vibrations and damping factors.

\begin{tabular}{|l|c|c|c|c|c|}
\hline Temple & $\begin{array}{c}\text { Height } \\
(\mathrm{m})\end{array}$ & $\begin{array}{c}\text { Main } \\
\text { Direction } \\
\text { Period } \\
(\mathrm{s})\end{array}$ & $\begin{array}{c}\text { Ridge } \\
\text { Direction } \\
\text { Period (s) }\end{array}$ & $\begin{array}{c}\text { Damping } \\
\text { Main } \\
\text { Dir. } \\
(\%)\end{array}$ & $\begin{array}{c}\text { Damping } \\
\text { Ridge } \\
\text { Dir. } \\
(\%)\end{array}$ \\
\hline Honjo Hachiman & 6.10 & 0.33 & 0.44 & 4.40 & 4.96 \\
\hline Shinzan & 6.70 & 0.37 & 0.50 & 3.42 & 8.00 \\
\hline Hie & 9.30 & 0.38 & 0.54 & 2.71 & 2.00 \\
\hline Tokusawa & 5.00 & 0.30 & 0.37 & 4.55 & 4.20 \\
\hline YashimaHachiman & 6.30 & 0.34 & 0.31 & 5.55 & 7.42 \\
\hline Konpira & 6.25 & 0.27 & 0.27 & 5.03 & 4.60 \\
\hline Shinmei & 7.13 & 0.32 & 0.45 & 2.89 & 2.42 \\
\hline Kiritoshi & 7.20 & 0.36 & 0.43 & 2.97 & 1.71 \\
\hline Omonoimi & 4.85 & 0.30 & 0.35 & 2.44 & 2.46 \\
\hline Suwa & 5.00 & 0.32 & 0.24 & 7.30 & 3.65 \\
\hline Kumano & 7.08 & 0.50 & 0.64 & 3.70 & 3.06 \\
\hline Inari & 4.37 & 0.32 & 0.43 & 3.92 & 2.49 \\
\hline
\end{tabular}

It can be noted that the general tendency is that periods for the ridge direction are longer than those obtained for main direction. These results are compared with the general tendency curve for traditional Japanese temples reported by Uchida et al. [1]. Figure 6 shows this comparison where the periods for each direction are plotted versus the height of the temple.

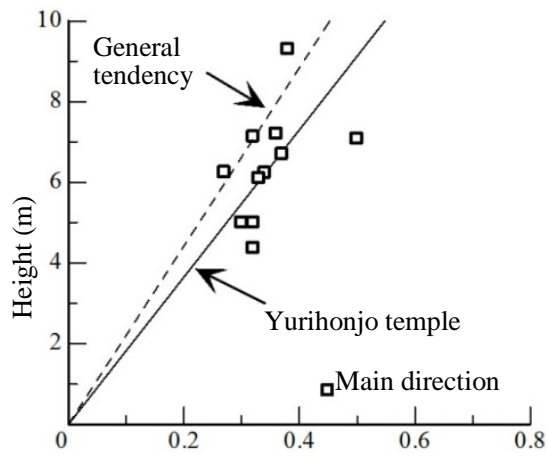

Period (s)

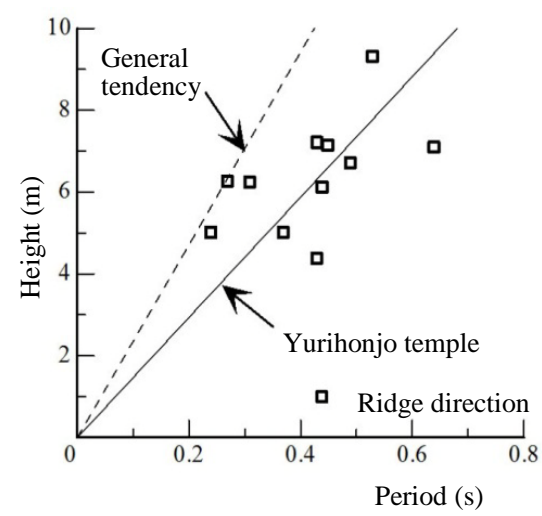

Figure 6: $\quad$ Periods of vibration versus temple heights.

Results for Hie, Yashima Hachiman and Konpira temples are on the curve of general tendency or a little above the curve. These temples were repaired at the foundation level and therefore this effect could be reflected in the measurements results. The results for other temples lay below the curve for both directions and 
it indicates the weakness of the temples with long period for the corresponding height. In general the selected temples show unbalanced values for period of vibration in each direction. For main direction the results are closer to the general curve and for the ridge direction the results differ more from the general curve as can be observed in Figure 6. Then for temples of this region the critical or weak direction is the ridge direction and therefore if some reparation work is planned it is necessary to consider the reinforcement of temples in the ridge direction.

The damping factor ranges from approximately $2 \%$ to $8 \%$. However in previous studies of other traditional temples smaller values of the order of $2 \%$ are reported. This fact could indicate that temples with high values of the damping factor present higher potential for energy dissipation. However, it is believed that the energy dissipation occurs due to the lack of appropriate stiffness of joints and supports and therefore could be an indicator of the vulnerability of the structure. When the damping factor is related to the period of the structure or to the height of the structure unclear relationships are obtained. Therefore, in this research the ratio of the number of spans versus the length is taken to establish a relation with the damping factor. That is the number of spans by unit length is plotted versus the value of the damping factor as is shown in Figure7.
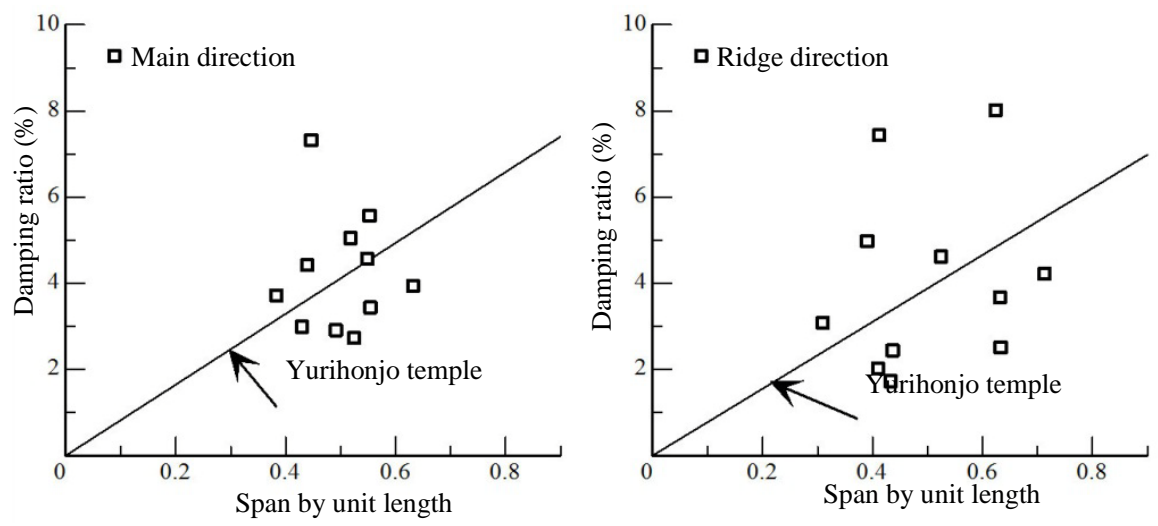

Figure 7: $\quad$ Number of span by unit length versus damping factor.

It can be noted that with the exception of one temple, the general tendency is to have a larger value of the damping factor when the number of span by unit length is increased. It is supposed that when the number of span by meter increases the structure presents more joints that could increase the dissipation of energy. However, the condition of the joints is an important factor as well as the distribution of joints along the height of the building which consider the presence of horizontal structural element like secondary beam.

The connection between the upper part of columns and roofs present in some case an intricate carpentry work (entablature) as is show in Figure 8. The effect of the connection between the columns and roof (joint type) on the damping factor is investigated by plotting separately the damping curves for those temples 
with entablature and without entablature. The results are shown in Figure 9. It was supposed that the intricate joint (with entablature) could have higher damping than the simple joint. However, the connections with entablature, apparently provides larger stiffness to the joint and therefore the damping becomes smaller.
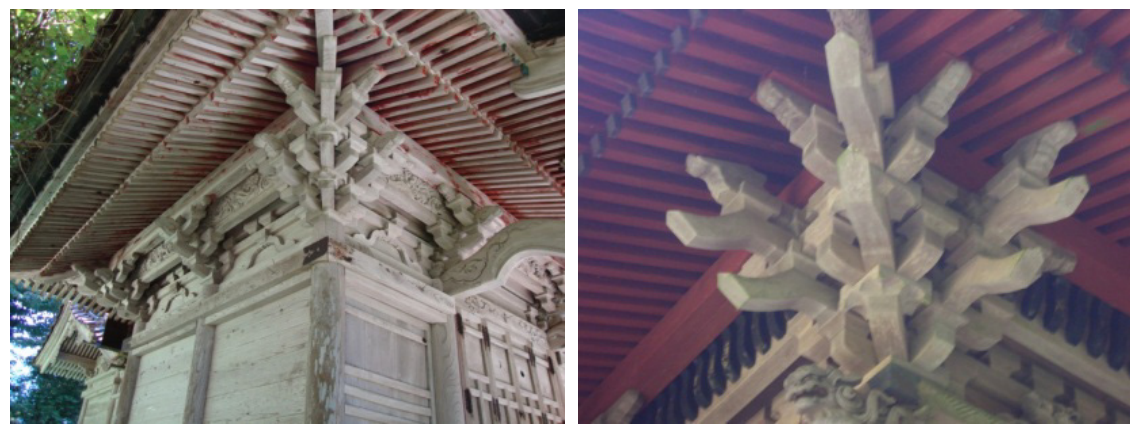

Figure 8: Detail of the entablature in the connection between column and roof.
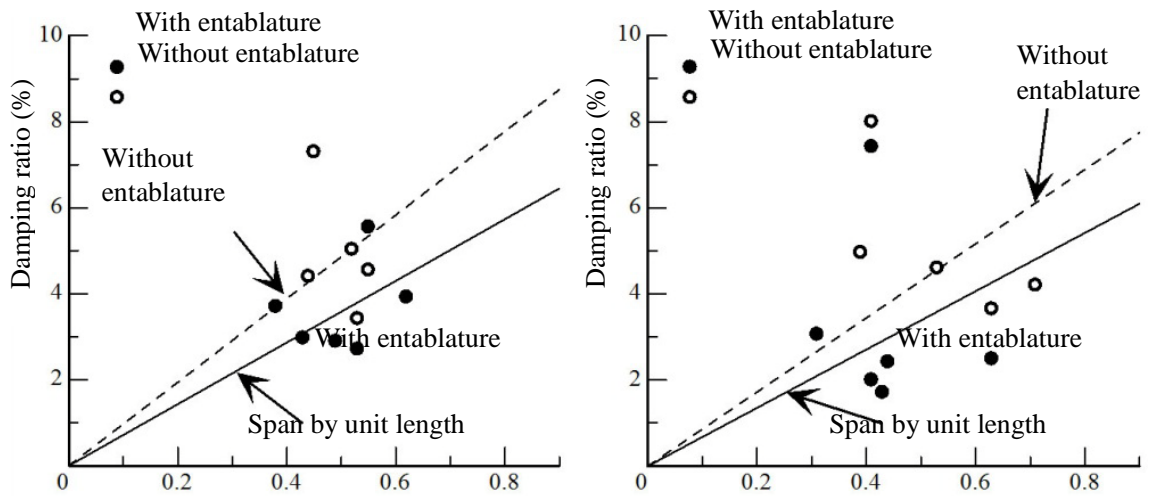

Figure 9: $\quad$ Number of span by unit length versus damping factor.

\section{Conclusions}

Ambient vibration measurements have been successfully employed to determine the dynamic characteristics of traditional Japanese wooden shrines of Yurihonjo city. The general tendency of the selected shrines is that periods for the ridge direction are longer than those obtained for main direction. These results compared with the general tendency curve for traditional Japanese shrines show that some shrines have longer period for the corresponding height. In addition, most of the temples show unbalanced results since for main direction the results are closer to the general tendency curve than results for ridge direction. In this 
case if some reparation work is planned it is necessary to consider the reinforcement of the temples in the ridge direction.

The damping factor were correlated with the number of spans of the structure and general tendency of increasing damping with increasing number of spans was found. However more analysis is required since it is believed that damping has strong dependency on the number of joints and on the conditions of these joints.

The connection between the upper part of columns and roofs with entablature gives smaller damping ratio probably due to constraint effect that provides additional stiffness with a decreasing on the capacity of the energy dissipation.

\section{References}

[1] Uchida, S., Maegawa, S. and Kawai, N. (2001). Vibration Characteristics of Traditional Wooden Heritages Structures. Summaries of Technical Papers of Annual Meeting, AIJ, Part 1 to Part 10 (in Japanese).

[2] C. Cuadra, K. Tokeshi, M. B. Karkee, Y. Sakaida; "Earthquake resistant of a historical brick building in Akita Prefecture, Japan”, Tenth International Conference on Structural Studies, Repairs and Maintenance of Heritage Architecture, STREMAH X, Prague, Jul. 2007, pp. 699-707.

[3] K. Ueta, C. Cuadra, K. Tokeshi, M. B. Karkee; "Seismic behavior of thatch house at Minehama village in Akita, Japan”, Tenth International Conference on Structural Studies, Repairs and Maintenance of Heritage Architecture, STREMAH X, Prague, Jul. 2007, pp. 667-673.

[4] C. Cuadra, M.B. Karkee, K. Tokeshi; "Earthquake risk to Inca's historical constructions in Machupicchu”, Advances in Engineering Software Volume 39 April 2008, Computational Modelling of Historical Constructions, pp. 336-345, ELSEVIER.

[5] C. Cuadra; "Seismic vulnerability of historical adobe buildings in the coast of Peru”, Eleventh International Conference on Structural Studies, Repairs and Maintenance of Heritage Architecture, STREMAH XI, Tallinn, Jul. 2009, pp. 455-463.

[6] C. Cuadra, C. Zavala, A. Abe, T. Saito, S. Sugano; Vibration characteristics of traditional adobe-quincha buildings located at Lima historic center, 8th International Conference on Urban Earthquake Engineering, March 7-8, 2011, Tokyo Institute of Technology, Japan. 